\title{
Genetic Divergence Study in Rice (Oryza sativa L.) Genotypes under Drought Condition
}

\author{
Shyama Kumari $^{1^{*}}$, S. B. Mishra ${ }^{2}$ and Nilanjaya ${ }^{1}$ \\ ${ }^{1}$ Department of Plant Breeding \& Genetics, Dr. Rajendra Prasad Central \\ Agricultural University, Pusa, Samastipur, Bihar, India \\ ${ }^{2}$ Tirhut college of Agriculture, Dholi, India \\ *Corresponding author
}

\section{A B S T R A C T}

\section{Keywords \\ Genetic diversity, Drought tolerant, Rice genotypes, Cluster analysis and $\mathrm{D}^{2}$ analysis}

Article Info

Accepted:

10 August 2020

Available Online:

10 September 2020
A field screening of thirty four drought tolerant rice genotypes was conducted during Kharif 2017 and Kharif 2018 with the objective to identify different genotypes under drought stress condition. Significant variation was observed among genotypes for all studied traits including leaf rolling, leaf drying and relative water content. The tolerant lines maintained high leaf water status, membrane stability and plant biomass under reproductive stage drought condition. All thirty four genotypes were distributed in nine clusters. Out of thirty four genotypes seventeen were placed in cluster I, eight in cluster II, three genotypes in cluster III while in rest of the clusters are mono genotype. The findings of this study indicate that the cluster III, IV, VI, VII and IX showed the higher distance under drought stress condition.

\section{Introduction}

Rice (Oryza sativa L.) is one of the world's most widely cultivated crop species and is staple food for more than half of the human population in the world and about two third in India. About 785 million tonnes of paddy which is 70 per cent more than the current production will be required to growing demand by 2025 (Manonmani and Khan, 2003a). Being staple food for majority of the population in India, improvement in its productivity has become crucial. The pace and magnitude of genetic improvement generally depend on the amount of genetic diversity present in a population and it is estimated that not even $15 \%$ of the potential diversity has utilized till date. We need to produce more rice per unit area. Achieving self sufficiency in rice production and maintaining price stability are important in countries where rice provides food security and generates employment and income for people (Hossain, 1995). About half of the world's rice area is under rainfed cultivation where drought is the major limiting factor to 
rice production globally. Rainfed area includes $13 \%$ upland ecosystem, $11 \%$ deepwater ecosystem and $25 \%$ rainfed lowland ecosystem of the total rice area (Fukai and Cooper, 1995). Drought is the second most sever limiting factor (Caldo et $a l .$, 1996). In upland rice, depth of rooting, root thickness and root-shoot dry weight ratio are related to drought resistance (Fukai and Cooper, 1995). Genetic divergence among the genotypes plays an important role in selection of parents having wider variability for different traits (Naik et al., 2004) and it also helps in the development of superior recombinants (Manonmani and Khan, 2003b). Therefore, the present study was undertaken to determine the genetic diversity of thirty four rice genotypes under drought condition.

\section{Materials and Methods}

Field experiments were carried out during Kharif 2017 and Kharif 2018 at Research Farm of Rajendra Central Agricultural University, Pusa, Samastipur, Bihar. Geographically, University Farm is situated between $25.98^{\circ} \mathrm{N}$ latitude and $85.67^{0}$ longitudes at $51.8 \mathrm{~m}$ above mean sea level. The experimental site was typical rainfed having clay loam soil with $\mathrm{pH}$ 7.5. Thirty four rice genotypes including check variety Sahbhagi dhan were evaluated for different morpho-physiological traits under drought stress condition. The rice genotypes used under present study were collected from RPCAU, PUSA (Bihar) and IRRI. Thirty four rice genotypes were grown under drought condition opting the direct seeded method under rainout shelter. The experiment was laid out in Completely Randomized Block Design with three replications. In each replication each genotype was grown in a plot of 5 rows of 1.5 meter length each with a spacing of $20 \mathrm{~cm}$ between rows under direct seeded condition using the fertilizer @ 80:40:40 kg (N: P: K) per ha. Nitrogen was applied on three stages $\left(1 / 3^{\text {rd }}\right.$ each at basal, maximum tillering and panicle initiation stage), while the $\mathrm{P}_{2} \mathrm{O}_{5}$ and $\mathrm{K}_{2} \mathrm{O}$ were applied as a basal application. The data were recorded on five randomly selected plants from each genotype in each replication leaving the first two border rows from all the four sides, in order to avoid the sampling error. The observations were recorded as per the following procedure. Readings from five plants were averaged replication wise and the mean data was used for statistical analysis for twenty one characters viz, Days to fifty per cent flowering, days to physiological maturity, plant height, number of tillers per plant, panicle length, panicle number per plant, number of grains per panicle, spikelet fertility, 1000 grain weight, leaf rolling at vegetative stage, leaf drying at vegetative stage, canopy temperature, chlorophyll content, relative water content, root length, root volume, fresh root weight, dry root weight, grain yield per plant, straw yield per plant and harvest index.

The drought scores leaf rolling and leaf drying observations were taken as per SES method, 1 to 9 scales (IRRI, 1996). Leaf relative water content (RWC) was estimated by recording the turgid weight of $0.5 \mathrm{~g}$ fresh leaf sample by keeping in water for $4 \mathrm{~h}$, followed by drying in hot air oven till constant weight is achieved (Weatherly, 1950). It is given as Relative water content $(\%)=[($ Fresh weight- Oven dry weight $) /$ (turgid weight- Oven dry weight) x 100]. Leaf chlorophyll content was recorded by measuring leaf greenness using a portal chlorophyll meter (Monilta Camera Co. Ltd., Japan). Canopy temperature was measured using a hand-held infrared thermometer. Measurements were taken in the afternoon (1:00 to 2:00) under full sunshine conditions. Yield attributes i.e. seed yield, straw yield, harvest index and dry matter was measured at maturity. 


\section{Data Analysis}

The morpho-physiological data were analyzed by appropriate statistical analysis (Gomez and Gomez, 1984) using WinStat 9.3 programme.

\section{Results and Discussion}

Analysis of variance (Table 1) revealed that significant differences among the genotypes for all the studied characters. The analysis from distance matrix gave nonhierarchical clustering among thirty four rice genotypes. All genotypes were grouped into nine clusters (Table 2). Cluster I had seventeen genotypes viz., IR 83140-B-11-B, IR 93856-10-2-3-2, IR10M243, IR 95793-5-2-2-3, IR 93827-291-1-2, IR 95785-15-2-1-2, IR14D197, Rajendra Bhagwati, IR 95785-31-2-1-2, GSR IR1-DQ62-D6-D1, Abhishek, IR 93849-22-31-1, IR 95817-14-1-1-2, GSR IR1-DQ150R5-Y1, IR 83142-B-19-B, IR 10G104 and IR 89889-34-2-1-1. Cluster I had maximum number of genotypes (17) followed by cluster II (8), cluster III (3) and one each in rest of the clusters. The thirty four rice genotypes taken for genetic divergence analysis differed significantly with regard to the characters studied and displayed marked divergence and grouped into nine clusters following Tocher's method (table 2). The clustering pattern showed that genotypes of same geographical areas were grouped in different clusters indicating that there was no formal relationship between geographical diversity and genetic diversity. The highest contribution in the manifestation of genetic divergence was exhibited by grain yield per plant (35.12) followed by straw yield per plant (24.6), fresh root weight (16.22), root volume (4.28) and panicle length (3.74) under drought condition (table 3). De and Rao (1987) and Singh et al., (1987) also revealed that geographical diversity is not necessarily related to genetic diversity. Intra and inter cluster distances are presented in (Table 4).
The inter cluster distances in almost all of the cases were larger than the intra cluster distances indicating that wider diversity was present among the genotypes of distant groups. Maximum intra cluster distance was obtained in cluster II followed by cluster I and cluster III and rest clusters did not impress intra cluster distance. These results are in agreement with those reported by Iftekharuddaula et al., (2002) and Kulsum et al., (2011) in rice. Maximum inter cluster distance was recorded between cluster III and Cluster IX followed by cluster V and Cluster IX, cluster VII and cluster IX, cluster IV and cluster IX cluster VII and IX as well as cluster I and Cluster IX and cluster III and cluster VIII while minimum inter cluster distance was recorded between cluster IV and cluster VI followed by cluster V, cluster VII and cluster I and cluster V suggesting that the genotypes belongs to cluster III and IX are more divergent among themselves. By using these genotypes heterotic recombinant may be developed. The results reported by Roy et al., (2002) and Naik et al., (2004) were agreement with these findings. The $\mathrm{D}^{2}$ value ranged from 0.32 to 2.49 under drought stress condition indicated a high degree of genetic diversity among the genotypes. Chaturvedi et al., (2011) and Chandra et al., (2007) also identified most diverse cluster based on intra and inter cluster distance and suggested their use in hybridization programme for achieving high yielding varieties. Cluster mean values for 21 characters are presented in Table 5. Difference in cluster means existed for almost all the characters studied. Among 21 characters, cluster III was maximum mean value for number of tillers per plant, panicle number per plant, number of grains per panicle, 1000 grain weight, grain yield per plant and straw yield per plant while minimum mean value for leaf rolling at vegetative stage and leaf drying at vegetative stage. Cluster IV was found maximum mean value for spikelet fertility, chlorophyll content 
and minimum mean value for canopy temperature. Cluster VI was rich for plant height may be selected as a donor for dwarfness, maximum mean value for panicle length and relative water content. Cluster VII was suitable for early days to fifty percent flowering and physiological maturity and maximum for harvest index. Cluster IX was suitable for maximum mean value for root length, root volume, fresh root weight and dry root weight. For the purpose of earliness, cluster VII is suitable genotypes to have the heterotic recombinant for yield and yield attributing traits under drought stress condition. Parents may be selected from cluster III and cluster IX.

Table.1 Analysis of variance for twenty one morpho-physiological traits in rice genotype under drought stress condition

\begin{tabular}{|c|c|c|c|c|}
\hline \multirow[t]{2}{*}{ S. No. } & \multirow[t]{2}{*}{ Characters } & \multicolumn{3}{|c|}{ Mean sum of squares } \\
\hline & & $\begin{array}{l}\text { Replication } \\
\quad(\text { d.f.=2) }\end{array}$ & $\begin{array}{c}\text { Treatments } \\
\quad(\text { d.f.=33) }\end{array}$ & Error \\
\hline 1 & DFF & 16.51 & $19.68 * *$ & 2.92 \\
\hline 2 & DPM & 10.16 & $23.55 * *$ & 5.49 \\
\hline 3 & PH & 5.18 & $120.14 * *$ & 40.72 \\
\hline 4 & NOTP $^{-1}$ & 48.73 & $23.21 * *$ & 6.18 \\
\hline 5 & PL & 27.85 & $15.63 * *$ & 2.31 \\
\hline 6 & PNP $^{-1}$ & 43.42 & $7.81 *$ & 4.45 \\
\hline 7 & NOGP $^{-1}$ & 187.71 & $3011.86^{* *}$ & 390.24 \\
\hline 8 & SF & 228.53 & $125.90 * *$ & 34.02 \\
\hline 9 & TGWT & 2.11 & $11.86 * *$ & 2.21 \\
\hline 10 & LR & 0.31 & $13.96 * *$ & 0.47 \\
\hline 11 & LD & 0.31 & $11.92 * *$ & 0.45 \\
\hline 12 & CT & 3.30 & $5.35 * *$ & 1.03 \\
\hline 13 & $\mathbf{C C}$ & 24.11 & $8.92 *$ & 4.63 \\
\hline 14 & RWC & 1475.62 & $198.17 * *$ & 82.96 \\
\hline 15 & $\mathbf{R L}$ & 7.11 & $5.12 * *$ & 1.33 \\
\hline 16 & RV & 2.51 & $652.74 * *$ & 22.65 \\
\hline 17 & FRW & 31.68 & $1238.35 * *$ & 22.36 \\
\hline 18 & DRW & 16.55 & $586.66^{* *}$ & 9.70 \\
\hline 19 & GYP $^{-1}$ & 50.58 & $809.78 * *$ & 36.02 \\
\hline 20 & $\mathbf{S Y P}^{-1}$ & 23.39 & $1157.60 *$ & 70.15 \\
\hline 21 & HI & 6.18 & $12.75 * *$ & 6.44 \\
\hline \multicolumn{3}{|c|}{ ** Significance at $1 \%$ level } & & \\
\hline \multicolumn{3}{|c|}{ * Significance at $5 \%$ level } & & \\
\hline
\end{tabular}


Table. 2 Clustering pattern of 34 drought tolerant genotypes of rice on the basis of $\mathrm{D}^{2}$ statistic

\begin{tabular}{|c|c|l|}
\hline $\begin{array}{c}\text { Cluster } \\
\text { No. }\end{array}$ & $\begin{array}{c}\text { No. of Genotypes } \\
\text { within cluster }\end{array}$ & \multicolumn{1}{|c|}{ Genotypes in cluster } \\
\hline I & 17 & $\begin{array}{l}\text { IR 83140-B-11-B, IR 93856-10-2-3-2, IR10M243, IR 95793-5-2-2- } \\
\text { 3, IR 93827-29-1-1-2, IR 95785-15-2-1-2, IR14D197, Rajendra } \\
\text { Bhagwati, IR 95785-31-2-1-2, GSR IR1-DQ62-D6-D1, Abhishek, } \\
\text { IR 93849-22-3-1-1, IR 95817-14-1-1-2, GSR IR1-DQ150-R5-Y1, } \\
\text { IR 83142-B-19-B, IR 10G104, IR 89889-34-2-1-1 }\end{array}$ \\
\hline II & & $\begin{array}{l}\text { IR 10A114, IRRI-123, IR 95817-5-1-1-2, Rajendra Nilam, IR } \\
\text { 93827-29-2-1-3, GSR IR1-DQ187-Y3-D1, IR 93810-17-1-2-3, GSR } \\
\text { IR1-DQ125-L2-D2 }\end{array}$ \\
\hline III & 3 & IR 91648-B-89-B-81-B, IR 95781-15-1-1-4, IR 95122:13-B-7-4-7-3 \\
\hline IV & 1 & IR 96279-33-3-1-2 \\
\hline V & 1 & IR 95795-53-1-1-2 \\
\hline VI & 1 & IR 91648-B-89-B-12-1-B \\
\hline VII & 1 & Sahbhagi Dhan (C) \\
\hline VIII & 1 & IR14D180 \\
\hline IX & 1 & GSR IR1-DQ139-R1-L2 \\
\hline
\end{tabular}

Table.3 Percent Contribution of twenty one morpho-physiological traits towards genetic divergence

\begin{tabular}{|c|c|c|c|}
\hline S. No. & Source & Times Ranked 1st & Contribution $\%$ \\
\hline 1 & Days to fifty percent flowering & 17 & 3.03 \\
\hline 2 & DPM Days to physiological maturity & 8 & 1.43 \\
\hline 3 & Plant height $(\mathrm{cm})$ & 2 & 0.36 \\
\hline 4 & Number of tillers plant ${ }^{-1}$ & 0 & 0 \\
\hline 5 & Panicle length $(\mathrm{cm})$ & 21 & 3.74 \\
\hline 6 & Number of panicle plant ${ }^{-1}$ & 2 & 0.36 \\
\hline 7 & Number of grains panicle ${ }^{-1}$ & 6 & 1.07 \\
\hline 8 & Spikelet fertility (\%) & 10 & 1.78 \\
\hline 9 & 1000 grain weight $(\mathrm{g})$ & 9 & 1.6 \\
\hline 10 & Leaf rolling (0-9 Scale) & 3 & 0.53 \\
\hline 11 & Leaf drying (1-9 Scale) & 3 & 0.53 \\
\hline 12 & Chlorophyll content & 14 & 2.5 \\
\hline 13 & Canopy temperature & 1 & 0.18 \\
\hline 14 & Relative water content $(\%)$ & 3 & 0.53 \\
\hline 15 & Root length $(\mathrm{cm})$ & 6 & 1.07 \\
\hline 16 & Root volume $\left(\mathrm{cm}^{3}\right)$ & 24 & 4.28 \\
\hline 17 & Root fresh wt. (g.) & 91 & 16.22 \\
\hline 18 & Dry fresh wt. (g.) & 5 & 0.89 \\
\hline 19 & $\mathrm{GYP}^{-1}$ Grain yield plant ${ }^{-1}(\mathrm{~g})$ & 197 & 35.12 \\
\hline 20 & Straw yield plant ${ }^{-1}(\mathrm{~g})$ & 138 & 24.60 \\
\hline 21 & Harvest-index (\%) & 1 & 0.18 \\
\hline
\end{tabular}


Table.4 Mean intra and inter cluster distance $\left(\mathrm{D}^{2}\right)$ among nine clusters in rice genotypes under drought stress condition

\begin{tabular}{|l|c|c|c|c|c|c|c|c|c|}
\hline \multicolumn{19}{|c|}{ Inter \& Intra Cluster Distances : Tocher Method } \\
\hline & $\begin{array}{c}\text { Cluste } \\
\text { r I }\end{array}$ & $\begin{array}{c}\text { Cluster } \\
\text { II }\end{array}$ & $\begin{array}{c}\text { Cluster } \\
\text { III }\end{array}$ & $\begin{array}{c}\text { Cluster } \\
\text { IV }\end{array}$ & $\begin{array}{c}\text { Cluster } \\
\text { V }\end{array}$ & $\begin{array}{c}\text { Cluste } \\
\text { r VI }\end{array}$ & $\begin{array}{c}\text { Cluster } \\
\text { VII }\end{array}$ & $\begin{array}{c}\text { Cluster } \\
\text { VIII }\end{array}$ & $\begin{array}{c}\text { Cluster } \\
\text { IX }\end{array}$ \\
\hline Cluster I & 0.28 & 0.76 & 0.8 & 0.45 & 0.39 & 0.51 & 0.45 & 0.61 & 1.41 \\
\hline Cluster II & & 0.39 & 1.5 & 1.17 & 1.21 & 0.76 & 1.15 & 0.5 & 0.51 \\
\hline Cluster III & & & 0.24 & 1.3 & 0.81 & 1.39 & 1.11 & 1.41 & 2.49 \\
\hline Cluster IV & & & & 0 & 0.52 & 0.32 & 0.47 & 0.88 & 1.82 \\
\hline Cluster V & & & & & 0 & 0.65 & 0.37 & 0.76 & 2.16 \\
\hline Cluster VI & & & & & & 0 & 0.6 & 0.65 & 1.28 \\
\hline Cluster VII & & & & & & & 0 & 0.94 & 1.84 \\
\hline Cluster VIII & & & & & & & & 0 & 0.72 \\
\hline Cluster IX & & & & & & & & & 0 \\
\hline
\end{tabular}

Table.5 Cluster mean values of nine clusters for twenty one morpho-physiological traits in rice genotypes under drought stress condition

\begin{tabular}{|l|l|l|l|l|l|l|l|l|l|l|l|}
\hline \multicolumn{10}{|c|}{ Cluster Means :Tocher Method $^{-1}$} \\
\hline & DFF & DPM & PH & NOTP $^{-1}$ & PL & PNP $^{-1}$ & NOGP $^{-1}$ & SF & TGWT & LR & LD \\
\hline Cluster I & 94.68 & 121.51 & 111.31 & 21.02 & 29.38 & 13.32 & 150.2 & 19.72 & 23.69 & 2.89 & 3.15 \\
\hline Cluster II & 95.25 & 121.78 & 111.66 & 21.36 & 29.52 & 13.58 & 153.23 & 19.97 & 23.70 & 2.79 & 3.04 \\
\hline Cluster III & 95.82 & 122.78 & 112.99 & 23.53 & 30.35 & 14.66 & 179.3 & 19.77 & 25.16 & 1.13 & 1.51 \\
\hline Cluster IV & 93.71 & 120.58 & 111.20 & 22.35 & 30.15 & 13.71 & 131.48 & 25.01 & 23.84 & 4.05 & 4.11 \\
\hline Cluster V & 94.12 & 121.08 & 112.35 & 22.41 & 30.31 & 12.77 & 141.75 & 18.13 & 23.14 & 2.93 & 3.22 \\
\hline Cluster VI & 94.38 & 121.33 & 109.15 & 21.86 & 31.93 & 13.69 & 149.93 & 19.29 & 23.13 & 4.04 & 4.19 \\
\hline Cluster VII & 92.00 & 117.42 & 113.56 & 21.46 & 29.62 & 13.17 & 154.78 & 14.3 & 24.37 & 3.30 & 3.76 \\
\hline Cluster VIII & 95.33 & 121.79 & 113.06 & 22.95 & 29.37 & 13.37 & 152.83 & 23.58 & 23.09 & 3.33 & 3.61 \\
\hline Cluster IX & 94.33 & 121.63 & 111.85 & 20.11 & 28.49 & 13.13 & 144.52 & 18.44 & 23.98 & 3.15 & 3.38 \\
\hline
\end{tabular}

\begin{tabular}{|l|l|l|l|l|l|l|l|l|l|l|}
\hline \multicolumn{10}{|c|}{ Cluster Means :Tocher Method } \\
\hline Cluster I & CT & CC & RWC & RL & RV & FRW & DRW & GYP $^{-1}$ & SYP $^{-1}$ & HI \\
\hline Cluster II & 35.18 & 42.99 & 50.96 & 10.31 & 17.88 & 22.74 & 13.39 & 40.18 & 56.34 & 41.2 \\
\hline Cluster III & 35.32 & 43.2 & 51.44 & 10.3 & 24.58 & 35.78 & 22.63 & 39.78 & 56.94 & 41.32 \\
\hline Cluster IV & 34.54 & 43.21 & 54.45 & 9.55 & 16.86 & 18.99 & 11.33 & 53.97 & 76.81 & 41.5 \\
\hline Cluster V & 36.4 & 42.29 & 51.35 & 9.69 & 15.4 & 18.49 & 10.32 & 41.98 & 55.9 & 40.21 \\
\hline Cluster VI & 34.56 & 43.01 & 58.01 & 9.74 & 18.92 & 26.11 & 16.02 & 34.62 & 54.24 & 40.56 \\
\hline Cluster VII & 35.35 & 42.58 & 50.79 & 10.27 & 14.43 & 20.46 & 11.91 & 40.91 & 56.16 & 41.87 \\
\hline Cluster VIII & 35.63 & 41.9 & 50.02 & 10.49 & 29.95 & 30.2 & 18.13 & 40.29 & 54.67 & 40.64 \\
\hline Cluster IX & 35.31 & 43.04 & 55.73 & 11.05 & 33.18 & 41.55 & 25.93 & 36.2 & 58.27 & 41.19 \\
\hline
\end{tabular}


Selection of genotypes based on cluster mean for the better exploitation of genetic potential also reported by Abarshahr, et al.(2011), Chaturvedi, et al., (2011), Raut et al., (2009), Ramya and Senthil kumar (2008), Arivoli et. al.(2009), Gahalain et al., (2010). Total divergence estimation based on $\mathrm{D}^{2}$ distances were also carried out by Hegde and patil (2000). Therefore, this cluster may be chosen for transferring the traits having high mean values through hybridization programme, that means the lines or varieties falling in cluster with maximum mean value having the potentialities to contribute better for maximizing yield of drought tolerant rice genotypes. It was clear from Table 5 that the highest intra cluster means for yield were obtained from clusters having maximum cluster mean resulting, giving more emphasis on these cluster for selecting genotypes as a variety and as well as parents in crossing with other genotypes. The character contributing the maximum to the divergence are given greater emphasis for deciding on the cluster for the purpose of further selection and the choice of parents for hybridization. In the present study, 34 diverse genotypes were grouped into various cluster and suitable diverse genotypes were selected based on their cluster mean superiority and per se performance for different characters resulting Sahbhagi Dhan grouped in cluster VII exhibited earliness in days to fifty percent flowering and days to physiological maturity based on cluster mean (lowest) and harvest index with highest cluster mean showed the significantly superior per se performance. The genotypes namely IR 91648-B-89-B-12-1-B was selected from cluster VI for plant height for dwarfness based on cluster mean and superior per se performance and also selected for high cluster mean for panicle length and relative water content. Cluster IV having genotype IR 96279-33-3-1-2 was selected for maintaining lower canopy temperature with least cluster mean and per se performance and also having highest cluster mean for spikelet fertility and chlorophyll content. Genotypes IR 91648-B-89-B-81-B, IR 95781-15-1-1-4 and IR 95122:13-B-7-4-7-3 from cluster III were selected for highest number of tillers per plant, panicle number per plant, number of grain per panicle, 1000 grain weight, grain yield per plant, straw yield per plant based on highest cluster mean with superior per se performance and also selected for minimum leaf rolling at vegetative stage and leaf drying at vegetative stage. Cluster IX having genotype GSR IR1-DQ139-R1-L2 was selected for root length, root volume, fresh root weight and dry root weight and superior per se performance. Similar results were reported by Rashidi et al., (2011). Genetically distant parents are usually able to produce higher heterosis and the clustering pattern could be utilized in choosing parents for cross combinations which are likely to generate the highest possible variability for effective selection of various economic traits. The findings of this study indicate that the cluster III, IV, VI, VII and IX showed the higher distance under drought stress condition. Parental materials selection from these clusters would give the manifestation of heterosis as well as wide spectrum of variation when they are hybridized.

\section{Acknowledgement}

Authors wish to acknowledge Department of Plant Breeding and Genetics, Dr. Rajendra Prasad Central Agricultural University (RPCAU) Pusa for providing materials and other supports.

\section{References}

Abarshahr, Mina, Rabiei B, Habibollah, Lahigi S. Assessing genetic diversity of rice varieties under drought stress conditions. Notulae Scientia Biologicae. 2011; 3(1):114-123.

Arivoli V, Saravanan K, Prakash M. A study on D2 analysis in rice. International Journal of 
Plant Sciences Muzaffarnagar. 2009; 4(1):157-160.

Caldo RA, Sabastian LS, Hernandez JE. Morphologybased genetic diversity analysis of Ancestral lines of rice in Philippine rice cultivars. Philippines Journal of Crop Sciences. 1996; 21(3):86-92.

Chandra R, Pradhan SK, Singh S, Bose LK, Singh $\mathrm{ON}$. Multivariate analysis in upland rice genotypes. World Journal of Agricultural Science. 2007; 3(3):295-300.

Chaturvedi HP, Talukdar P, Sapu C. Genetic divergence in lowland rice (Oryza sativa L.) genotypes of Nagaland. Environment and Ecology. 2011; 29(1):27-29.

De RN, Rao AVS. Genetic divergence in rice under low land situation. Crop improvement. 1987; 14(2):128-131.

Fukai S, Cooper M. Developments of drought resistant cultivars using physiomorphological traits in Rice. Field crops and research. 1995; 40:67-86.

Gahalain SS, Deepti B, Anita G. Genetic divergence in rice (Oryza sativa $\mathrm{L}$.) cultivars grown in Kumaun Hills. Vegetos-. 2010; 23(1):83-88.

Gomez KA, Gomez AA. Statistical Procedures for Agricultural Research. John Wiley \& Sons Inc., Singapore, 2nd Edn, 1984.

Hegde SG, Patil CS. Genetic divergence in rainfed rice. Karnataka Journal of Agricultural Sciences. 2000; 13(3):549-553.

Hossain M. Sustaining the food security for fragile environments in Asia: achievement, challenges and implications for rice research, In: fragile lives in fragile ecosystems. Proceeding International Rice research Conference, 13-17 FEB 1995, Manila, Philippines. International Rice Research Institute. 1995, 3-23.

Iftekharuddaula KM, Akter K, Bashar MK, Islam MR. Genetic parameters and cluster analysis of panicle traits in irrigated rice. Bangladesh Journal of Plant Breeding and Genetics. 2002; 15(1):49-55.

IRRI. Standard evaluation system for rice. International Rice Research Institute, Los Banos, Philippines, 1996.

Kulsum MU, Hasan M, Begum JH, Billah MM, Rahman H. Genetic diversity of some restorer lines for hybrid rice development. Bangladesh Journal of Agricultural research. 2011; 36(1):21-28.

Manonmani S, Fazlullah Khan AK. Studies on combing ability and heterosis in rice. Madras Agric. J. 2003a; 90:228-231.

Naik AR, Chaudhury D, Reddy JN. Genetic Divergence studies in scented rice. Oryza. 2004; 40:79-82.

Ramya K, Senthilkumar. Genetic divergence in rice. Crop Improvement. 2008; 35(2):119121.

Rashidi V, Yani SC, Tarinejad AR. Evaluation of drought tolerance in promising lines and cultivars of bread wheat (Triticum aestivum L.). Journal of Food Agriculture and Environment. 2011; 9(1):423-427.

Raut KR, Harer PN, Yadav PS. Genetic divergence in rice. Journal of Maharashtra Agricultural Universities. 2009; 34(2):172174.

Roy B, Basu AK, Mandal AB. Genetic diversity in rice genotypes under humid tropics of Andaman based on grain yield and seed characters. India J Agril. Sci. 2002; 72:8487.

Singh SK, Singh RS, Maurya DM, Verma OP. Genetic divergence among the low land rice cultivars. India Journal of Genetics. 1987; 39:315-322.

Weatherley, P. E. Studies in the water relations of the cotton plant. New Phytol. 1950; 49, i:8198 .

\section{How to cite this article:}

Shyama Kumari, S. B. Mishra and Nilanjaya. 2020. Genetic Divergence Study in Rice (Oryza sativa L.) Genotypes under Drought Condition. Int.J.Curr.Microbiol.App.Sci. 9(09): 825-832. doi: https://doi.org/10.20546/ijcmas.2020.909.104 